BNWL-289

\title{
POSSIBLE OPTIMUM USE OF THORIUM AND URANIUM EMPLOYING CROSSED - PROGENY FUEL CYCLES
}

E. A. Eschbach

D. E. Deonigi

May, 1966

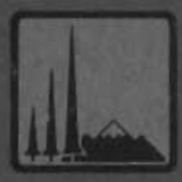

\section{Battelle=NoRthWest}

BATTELLE MEMORIAL. INSTITUTE / PACIFIC NORTHWEST LABORATORY 


\section{LEGAL NOTICE}

This report was prepared as an account of Government sponsared work. Neither the United States, nor the Commission, nor any person acting on behalf of the Commission:

A. Makes any warranty or representation, expressed or implied, with respect to the accuracy, completeness, or usefulness of the information contained in this report, or that the use of any information, apparatus, method, or process disclosed in this report may not infringe privately owned rights; or

B. Assumes any liabilities with respect to the use of, or for damages resulting from the use of any information, apparatus, method, or process disclosed in this report.

As used in the above, "person acting on behalf of the Commission" includes any employee or contractor of the Commission, or employee of such contractor, to the extent that such employee or contractor of the Commission, or employee of such contractor prepores, disseminates, or provides access to, any information pursuant to his employment or contract with the Commission, or his employment with such contractor.

\section{PACIFIC NORTHWEST LABORATORY \\ RICHLAND, WASHINGTON \\ operated by \\ BATTELLE MEMORIAL INSTITUTE}

for the

UNITED STATES ATOMIC ENERGY COMMISSION UNDER CONTRACT AT(45-1)-1830 
BNWL-289

UC-80, Reactor Technology

\author{
POSSIBLE OPTIMUM USE OF THORIUM AND URANIUM \\ EMPLOYING CROSSED-PROGENY FUEL CYCLES
}

By

E. A. Eschbach

D. E. Deonigi

\begin{abstract}
Advanced Concepts and Analysis Section
\end{abstract}
Mathematics Department

May 1966

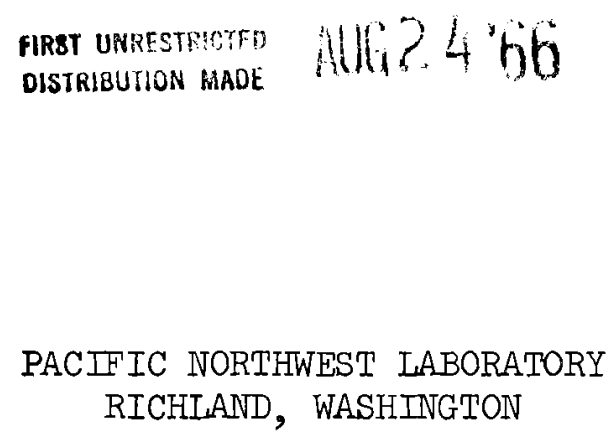


Printed in the USA. Price $\$ 2.00$. Available from the Clearinghouse for Federal Scientific and Technical Information National Bureau of Standards

U. S. Department of Commerce, Springfield, Virginia 


\section{LIST OF FIGURES}

Figure Number

1

Title

$\underline{\text { Page }}$

The Isotopic Buildup in Thorium and $U^{238}$ Systems . . 2 Eta of Fissile Isotopes for Various Reactor Spectrums ............... 5

The Fate of 100 Atoms of $\mathrm{U}^{233}$ or Pu239 in Optimized Reactor Systems Without Neutron Losses . . . . . 7 The Fate of 100 Atoms of $\mathrm{Pu}^{239}$ or $\mathrm{U}^{233}$ in Optimized Reactor Systems Without Neutron Losses . . . . 9 Average Conversion Ratios and Enrichments of Optimized U $^{233-N a t u r a l ~ U r a n i u m ~ a n d ~ P u-T h o r i u m ~ F u e l s ~ . ~ . ~ . ~ . ~} 12$ Minimum Fuel Cost as a Function of Moderator-to-Fuel Ratio for Various LWR Fueling Systems . . . . . . 14 Fuel Cycle Costs and Average Conversion Ratios for Optimized LWR and HWR Fuels . ......... 15 The Effect of Thorium Density on the Fuel Cycle Cost of a PWR ............... 18 Properties of Ternary Fuels....... 20 The Infinite Multiplication Factor as a Function of Exposure for a Reduced Density Ternary Fuel .... 21 


\title{
POSSIBLE OPTIMUM USES OF THORIUM AND URANTUM EMPLOYING CROSSED-PROGENY FUEL CYCLES*
}

\author{
E. A. Eschbach \\ D. E. Deonigi
}

In this paper, we will consider how the advantages of thorium and uranium fuel cycles might be combined so that thorium could be more economically used in thermal reactors. of current design.

Thorium and natural uranium both have about the same mining costs, but natural uranium contains some fissile material, 1 part in 139, whereas thorium has none. Hence the cost to enrich thorium is higher. Cost, therefore, is the reason that most thermal reactors use uranium instead of thorium as a fertile material. This cost disadvantage is emphasized because the United States already has a sizeable nuclear industry oriented toward the use of slightly enriched uranium.

This cost disadvantage, however, might be overcome by maximizing the virtues of the thorium and uranium fuel cycles. One way to do this maximizing would be to cross the fissile progeny of thorium and U-238 so that the plutonium formed from U-238 would serve as enrichment for thorium, and the U-233 formed from thorium would serve as enrichment for U-238. However, before showing how such crossed-progeny fuel cycles would maximize the virtues of the thorium and uranium fuel cycles, let us first consider both the buildup of plutonium in U-238 and the buildup of U-233 in thorium.

The first thing we notice in Figure 1 is the striking parallel that exists between the two series: Both series begin with an abundant fertile material; and when Th-232 and U-238 capture a neutron, they form a new isotope that beta-decays to form a fissile isotope--U-233 or Pu-239; thereafter, each series has the same rhythm of fertile isotope, fissile isotope,

* This paper was presented at the Second International Thorium Fuel Cycle Symposium held at Oak Ridge National Laboratory, Gatlinburg, Tennessee, May 3-6, 1966. 
Figure 1

THE ISOTOPIC BUILDUP IN THORIUM AND $U^{238}$ SYSTEMS

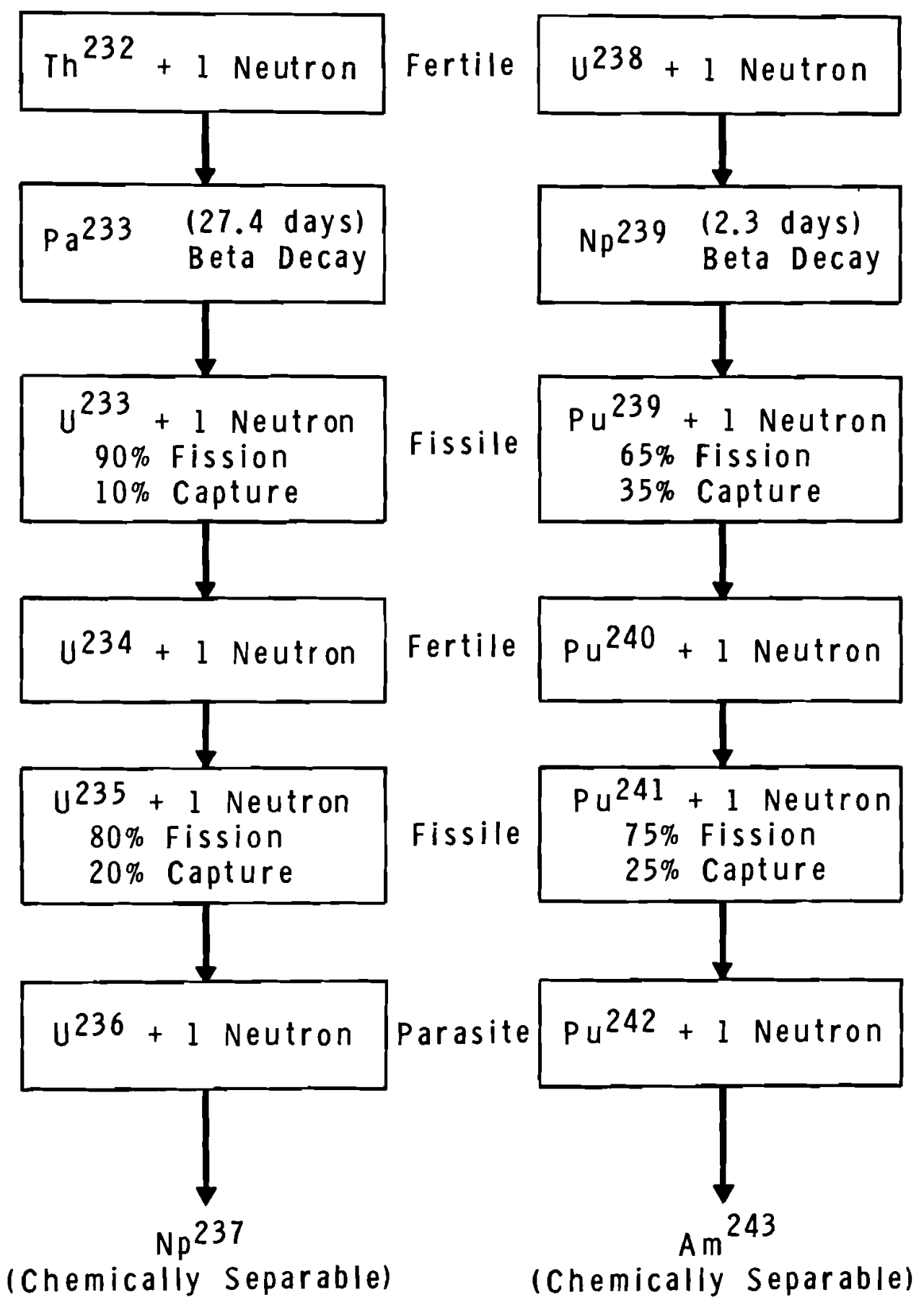


and parasite, which terminates the chain when it captures a neutron to form a chemically separable isotope.

But if we consider more closely the isctopic properties in each series, we find some significant differences. U-238, for example, has a much larger fast fission cross section, or fast effect, than thorium. The fast effect is important because it produces both neutrons and heat from an inexpensive material. Now when U-238 captures a neutron, it forms Np-239; and when thorium captures a neutron, it forms $\mathrm{Pa}-233$. Here again, we observe a difference: Pa-233 has a much longer half-life than Np-239; Pa-233 also has a larger absorption cross section, which includes a sizeable resonance integral. So the probability of Pa-233 absorbing a neutron to form U-234 instead of U-233 is much greater than the probability of Np-239 absorbing a neutron to form Pu-240 instead of Pu-239. And this probability of $\mathrm{Pa}-233$ forming nonfissile U-234 instead of fissile U-233 becomes a serious problem if the flux level is very high or if the neutron spectrum is very hard. U-233 and Pu-239, the next isotopes in the series, are both fissile, but their characteristics are also distinctly different. In the thermal neutron spectrum, U-233 has a much lower alpha $\left(\sigma_{c} / \sigma_{f}\right)$ and therefore a higher eta $[v /(1+\alpha)]$ than Pu-239. This difference in eta, however, is not as large as the difference in alpha might suggest, because Pu-239 has a larger $v$, or a larger number of neutrons produced per fission. Our next observation is that Pu-239, because it has a higher alpha, produces 3.5 times more of the fertile isotope Pu-240 than U-233 produces of the fertile isotope U-234. And when comparing the fertile materials Pu-240 and U-234, we find that Pu-240 has a much larger cross section, possibly making it the more valuable of the two fertile isotopes. And after each of these two fertile materials absorbs a neutron, two new fissile isotopes are formed--namely, $\mathrm{U}-235$ and Pu-241. Here the difference in alpha is small, and it seems to favor the thorium series. The difference in $v$, however, causes Pu-24I to have the larger eta; and this larger eta of Pu-24I over U-235 tends to reduce the net effect of the larger eta of U-233 over Pu-239. Pu-241, moreover, has a larger cross section than U-235. However, the 13-year half-Iife of Pu-24I means that some Pu-24I will be lost by decay. As for the percentage of fissions to the percentage of captures in thermal reactors, 
Pu-241 forms Pu-242 abcut 25\% of the time, whereas U-235 forms U-236 about $20 \%$ of the time. Both $\mathrm{J}-236$ and $\mathrm{Pu}-242$ are parasites because they require the absorption of still another neutron to proauce another nonfissile, nonfertile isotope. These nonfissile, nonfertile isotopes--Np-237 and Am-243--are both chemically separable and terminate their respective series. Even though we have described U-236 and Pu-242 as parasites, it should be noted that both of them would become valuable if a market ever exists for transuranium heat-source isctopes. In that event, Np-237 and Am-243 targets would be irradiated to form Pu-238 and Cm-244, respectively.

Now let us take an even more detailed look at the two sets of fissile isotopes, as shown in Figure 2 .

In particular, let us consider the effect of neutron spectrum on eta, which is the ratio of the neutrons produced to the neutrons absorbed. Note that the figure shows the computed eta values for four spectral indexes and three neutron temperatures. The spectral index of 0.05 represents a well-moderated reactor; the spectral indexes of 0.15 and 0.25 , typical power reactors; and the spectral index of 0.35 , a power reactor using a highly enriched fuel. Now when considering temperatures, we should keep in mind that the neutron temperature of $100^{\circ} \mathrm{C}$ relates to a heavy water moderated reactor ( $H W R$ ), the $400^{\circ} \mathrm{C}$ neutron temperature relates to a light water moderated reactor ( $\mathrm{LWR}$ ), and the $1000^{\circ} \mathrm{C}$ temperature relates to a high temperature gas cooled reactor (ITGCR).

Looking at the isotope U-233, we see that its eta changes little when either the spectral index or the neutron temperature increases. This is in marked cortrast with Pu-239, whose eta changes considerably when either the temperature or the spectral index increases.

As for the eta of $U-235$, we see that it has only a small reduction when the temperature increases, but a significant reduction when the spectrum hardens. It should be pointed out, however, that the concentrations of U-235 used in these calculations are typical of the dilute quantities produced from U-234 captures; and these dilute U-235 quantities are only one-tenth of the U-235 concentrations in normal water reactor fuels. Thus the self-shielding of the U-235 resonance here is very small when compared to the self-shielding in U-235 enriched fuel. 
Figure 2

ETA OF FISSILE ISOTOPES FOR VARIOUS REACTOR SPECTRUMS

\begin{tabular}{|c|c|c|c|c|}
\hline \multirow[t]{2}{*}{$\begin{array}{c}\text { Spectral } \\
\text { Index "r" }\end{array}$} & $u^{233}$ & $u^{235}$ & $\mathrm{Pu}^{239}$ & $\mathrm{Pu}^{241}$ \\
\hline & - Neut & Temperature 100 & ${ }^{0} \mathrm{C}$ & \\
\hline $\begin{array}{l}0.05 \\
0.15 \\
0.25 \\
0.35\end{array}$ & $\begin{array}{l}2.27 \\
2.26 \\
2.23 \\
2.22\end{array}$ & $\begin{array}{l}2.06 \\
2.01 \\
1.97 \\
1.94\end{array}$ & $\begin{array}{l}2.06 \\
2.00 \\
1.96 \\
1.93\end{array}$ & $\begin{array}{l}2.24 \\
2.24 \\
2.23 \\
2.22\end{array}$ \\
\hline & Neut & Temperature 400 & ${ }^{\circ} \mathrm{C}-$ & \\
\hline $\begin{array}{l}0.05 \\
0.15 \\
0.25 \\
0.35\end{array}$ & $\begin{array}{l}2.26 \\
2.24 \\
2.22 \\
2.20\end{array}$ & $\begin{array}{l}2.04 \\
1.98 \\
1.94 \\
1.89\end{array}$ & $\begin{array}{l}1.95 \\
1.92 \\
1.90 \\
1.88\end{array}$ & $\begin{array}{l}2.20 \\
2.20 \\
2.20 \\
2.20\end{array}$ \\
\hline & - Neut & Temperature 1000 & ${ }^{0} \mathrm{C}$ & 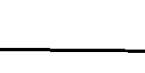 \\
\hline $\begin{array}{l}0.05 \\
0.15 \\
0.25 \\
0.35\end{array}$ & $\begin{array}{l}2.25 \\
2.23 \\
2.20 \\
2.19\end{array}$ & $\begin{array}{l}2.01 \\
1.95 \\
1.89 \\
1.83\end{array}$ & $\begin{array}{l}1.87 \\
1.87 \\
1.87 \\
1.86\end{array}$ & $\begin{array}{l}2.12 \\
2.15 \\
2.17 \\
2.20\end{array}$ \\
\hline
\end{tabular}


Pu-24l is the second fissile plutonium isotope shown in Figure 2. Although some uncertainties still exist, our data for Pu-24l indicate a very small eta variation when the temperature or the spectrum changes. The one exception is in the $1000^{\circ} \mathrm{C}$ neutron temperature range. The reason the $\mathrm{Pu}-241$ eta increases there is that a higher percentage of the reactions are taking place above the $0.3 \mathrm{eV}$ resonance.

From what has been shown thus far, we can conclude, without considering special fuel configurations*, that plutonium performs best in a soft spectrum and at a low neutron temperature--two characteristics which are typical of HWR designs. We can conclude further that, since spectrum changes do not affect the eta of $U-233$, the reactor in which U-233 is used could maximize some other fuel or reactor characteristic. For example, U-233 used in an HTGCR would allow the thermal-toelectrical efficiency of that reactor to be maximized; or U-233 used in a tight lattice LWR would allow the U-238 fast effect to be maximized.

Figure 3 shows both the fate cf 100 atoms of U-233 enriching thorium in an idealized HWR, and the fate of 100 atoms of Pu-239 enriching U-238 in an idealized LWR. If we examine the box on the left, we see that 100 neutrons absorbed in U-233 produce 223 neutrons, forming at the same time 11 atoms of $\mathrm{U}-234$. In its turn, U-234 absorbs 11 neutrons that produce 11 atoms of U-235. These U-235 atoms absorb an additional 11 neutrons, 9 of which cause fission, producing 19 more neutrons. And the two U-236 atoms formed from the two U-235 captures absorb two more neutrons to terminate the series. Thus there are a total of 124 neutrons absorbed and 242 neutrons gained, leaving an excess of 118 neutrons for absorption in Th-232, which, as shown at the top of the left-hand column above the box, also absorbs 2 neutrons from the thorium fast effect. And since $\mathrm{Pa}-233$ captures two neutrons, the potential conversion ratio of a U-233-thorium fuel when there are no neutron losses is $118 / 100$, or 1.18 . Turning now to the other box, in which is shown the fate of $100 \mathrm{Pu}-239$

* Such as the pencil lead configurations described at the American Nuclear Society 1965 Winter Meeting. (See the Battelle-Northwest Report entitled Some Novel Plutonium Fueling Methods for Thermal Reactors, BNWL-183, November 1965.) 
Figure 3

- THE FATE OF 100 ATOMS OF $U^{233}$ OR PU 239 IN OPTIMIZED REACTOR SYSTEMS WITHOUT NEUTRON LOSSES

\begin{tabular}{|c|c|}
\hline $\begin{array}{l}U^{233} \text {-Thorium in an optimized HWR } \\
(\epsilon=1.01)\end{array}$ & $\begin{array}{c}\text { Pu-U } \\
\text { in an 0ptimized LWR } \\
(\epsilon=1.05)\end{array}$ \\
\hline
\end{tabular}

Atoms Neutrons "in" Neutrons "out" \% Heat

$\begin{array}{lcr}\mathrm{Th}^{232} & 120 & 120 \\ \mathrm{~Pa}^{233} & 120 & 2 \\ \mathrm{U}^{233} & 118^{*} & \\ \text { Formed } & \end{array}$

\begin{tabular}{|cccc|}
\hline$u^{233}$ & 100 & 100 & 223 \\
$u^{234}$ & 11 & 11 & \\
$u^{235}$ & 11 & 11 & 19 \\
$u^{236}$ & 2 & $\frac{2}{124}$ & $\frac{242}{2}$ \\
\hline
\end{tabular}

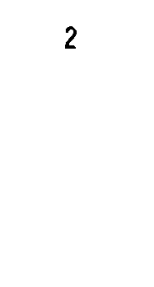

$\begin{array}{lcl}\mathrm{U}^{238} & 99 & 99 \\ \mathrm{~Np}^{239} & 99 & 0 \\ \mathrm{Pu}^{239} & 99^{*} & \\ \text { Formed } & \end{array}$

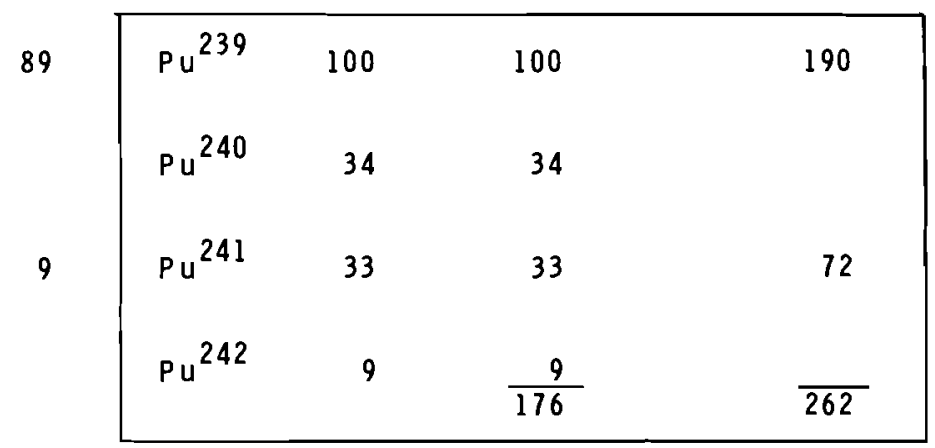

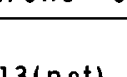

13(net)

$\%$ Heat

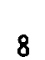

8

67

25

*Initial Conversion Ratio $=\underline{1.18}$ for $U^{233}-$ Thorium

$=\underline{0.99}$ for $\mathrm{Pu}-\mathrm{U}^{238}$

$$
\begin{aligned}
\eta \epsilon & =\left(\frac{242}{100+11}\right)(1.01)=\underline{2.20} \text { for } U^{233}-\text { Thorium } \\
& =\left(\frac{262}{100+33}\right)(1.05)=\underline{2.07} \text { for } P u-U^{238}
\end{aligned}
$$


atoms, we obtain 262 neutrons from 176 neutrons absorbed, leaving an excess of 86 neutrons to be absorbed in U-238. And because of the U-238 fast effect, 13 more neutrons become available to form 99 atoms of new Pu-239. Thus the potential conversion ratio for the idealized plutonium-U-238 system is 0.99. Comparing the two idealized conversion ratios, it is evident that the U-233-thorium system has a potential conversion ratio $20 \%$ higher than that of the Pu-U-238 system. As for the percentage of heat produced, we see that U-233 produces nearly $90 \%$ of the heat in U-233-thorium fuel, whereas Pu-239 produces only 67\% in the U-233-U-238 fuel.

We will now show how crcssing the progeny of the U-233-thorium and Pu-U-238 systems, as represented by the two boxes just shown, will maximize the virtues of both the fertile and the fissile materials.

The first thing to remember in Figure 4 is that the HWR spectrum has been slightly softened to better accommodate the plutonium enrichment. Furthermore, the lattice spacing of the LWR has been tightened to maximize the fast effect of U-238. Tightening the lattice, by the way, will reduce the water volume, and hence increase thermal utilization. Moreover, the reactor power per unit volume will be significantly increased if the lattice is tightened.

Starting again with the box to the left of the figure, we see that plutonium in the HWR spectrum produces 269 neutrons for 163 neutrons absorbed, leaving an excess of 105 neutrons to be absorbed by Th-232. Three more neutrons are gained from the thorium fast effect, but one of these is lost to Pa-233 absorption. Hence the number of U-233 atoms formed from 100 atoms of Pu-239 is 107, which is equal to a conversion ratio of 1.07 . Thus the conversion ratio of plutonium-thorium is $10 \%$ less than that of U-233-thorium, and the eta epsilon is $4 \%$ less, or 2.20 for U-233-thorium and 2.12 for plutonium-thorium. These comparisons show that a small reduction in neutron availability occurs when plutonium instead of U-233 is used to enrich thorium. However, this small reduction will be more than offset by the gain in conversion ratio of U-233-U-238, as the box to the right of the figure shows. This box 
Figure 4

THE FATE OF 100 ATOMS OF PU ${ }^{239}$ OR $U^{233}$ IN OPTIMIZED REACTOR SYSTEMS WITHOUT NEUTRON LOSSES

Pu-Thorium in an optimized HWR

$(\epsilon=1.01)$

Atoms Neutrons "in" Neutrons "out" \% Heat

$$
\begin{gathered}
U^{233}-U^{238} \text { in an optimized LWR } \\
(\epsilon=1.10)
\end{gathered}
$$

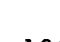

108

$3($ net)

3

Atoms Neutrons "in" Neutrons "out"

\% Heat

$\begin{array}{ll}\mathrm{Th}^{232} & 108 \\ \mathrm{~Pa}^{233} & 108 \\ \mathrm{U}^{233} & 107^{*} \\ \text { Formed } & \end{array}$

\begin{tabular}{|cccc|}
\hline $\mathrm{Pu}^{239}$ & 100 & 100 & 205 \\
$\mathrm{Pu}^{240}$ & 29 & 29 & \\
$\mathrm{Pu}^{241}$ & 28 & 28 & 64 \\
$\mathrm{Pu}^{242}$ & 7 & $\frac{7}{164}$ & $\frac{269}{}$ \\
\hline
\end{tabular}

*Initial Conversion Ratio $=\underline{1.07}$ for Pu-Thorium

$=\underline{1.42}$ for $u^{233}-u^{238}$

$$
\begin{aligned}
\eta \in & =\left(\frac{269}{100+28}\right)(1.01)=\underline{2.12} \text { for } \mathrm{Pu} \text {-Thorium } \\
& =\left(\frac{242}{100+11}\right)(1.10)=\underline{2.40} \text { for } \mathrm{U}^{233}-\mathrm{U}^{238}
\end{aligned}
$$


indicates that the number of neutrons available for U-238 absorption is equal to 242 neutrons produced minus 124 neutrons absorbed, plus 24 neutrons gained from the U-238 fast effect. The conversion ratio of U-233$\mathrm{U}-238$, therefore, is 1.42 , as compared to a 0.99 conversion ratio of PuU-238 when no neutrons are lost, or a gain of $42 \%$. A significant increase is also seen in the percent of heat derived from the larger U-238 fast effect of U-233-U-238. In fact, it nearly doubles, going from $8 \%$ in plutonium-U-238 to $15 \%$ in $\mathrm{U}-233-\mathrm{U}-238$.

Thus far we have considered idealized reactors that have no neutron losses. Now we will consider the conversion ratios of reactors that do have neutron losses. Moreover, we will no longer use pure U-238 as a term in our comparisons. The new comparison term will now be the more realistic natural uranium.

It should be noted that, although U-233-natural uranium fuel has the economic advantage of the inexpensive fissions from U-235 in natural uranium, the conversion ratio of U-233-natural uranium will be less than that of U-233-U-238. Furthermore, if U-233 can be easily separated from U-233-natural uranium after the fuel is burned, the economic advantage of the inexpensive U-235 fissions can be maintained. But if the separation of the U-233 and U-235 cannct be maintained, the fuel-cycle cost penalty, according to our calculations, will only be about $0.05 \mathrm{mill} / \mathrm{kWh}$, while the conversion ratio will be higher.

Before going on to Figure 5, we should say something about the reactivity swing both of U-233-natural uranium and of plutonium-thorium in a reactor designed for slightly enriched uranium fuel. Both U-233-natural uranium and U-235-natural uranium have a reactivity swing that is less than that of plutonium-thorium. The general reason for this is that U-233 or U-235 have a microscopic fission cross section that is smaller than that of plutonium. More particularly, the macroscopic fission cross section of U-233-natural uranium or U-235-natural uranium remains more constant during burnup than the macroscopic fission cross section of plutonium. To understand why this is so, let it be recalled that the macroscopic fission cross section is equal to the sum of the fissile atoms 
multiplied by their corresponding effective microscopic fission cross sections. Now during the burnup of U-233-natural uranium or U-235-natural uranium, the destroyed U-233 or U-235 atoms, which have a low microscopic fission cross section, are being partly replaced with plutonium atoms, which have a high microscopic fission cross section. But just the opposite happens during the burnup of plutonium-thorium fuel: the destroyed plutonium atoms, which have a high microscopic fission cross section, are being partly replaced with U-233 atoms, which have a low microscopic fission cross section. Furthermore, plutonium-thorium systems generally have a lower conversion ratio than that of U-233-natural uranium or U-235-natural uranium. Thus as burnup proceeds, the macroscopic fission cross section of plutonium-thorium fuel is further reduced, which increases the reactivity swing。

It is also interesting to note that one way to reduce the reactivity swing of plutonium-thorium in an HWR is to refuel the HWR at frequent intervals. Morecver, computations indicate that the reactivity swing of plutonium-thorium in an HTGCR could be made equal to or less than that of slightly enriched uranium by decreasing the amount of graphite in the reactor--which would harden the spectrum. At the neutron temperatures characteristic of HTGCR's, hardening the neutron spectrum would both increase the fertile material cross section and decrease the fissile material cross section.

Our work in other studies of plutonium-enriched fuel shows that (1) the large reactivity swing of plutonium-enriched fuel is often due to a low Pu-240 content in the initial plutonium enrichment; (The PRTR and EBWR had to use plutonium whose Pu-240 content was low, because none other was available. Fortunately, however, the piutonium available from PWR's and BWR's has a substantial amount of Pu-240.) and (2) minor adjustments in the effective moderator-to-fuel density will usually make the reactivity swing of plutonium-enriched fuel equal to or less than that of slightly enriched uranium.

Figure 5 shows how the buildup of plutonium and fission products affects the conversion ratio of U-233-natural uranium. We can see that a conversion ratic of 0.94 can be maintained through an exposure of 


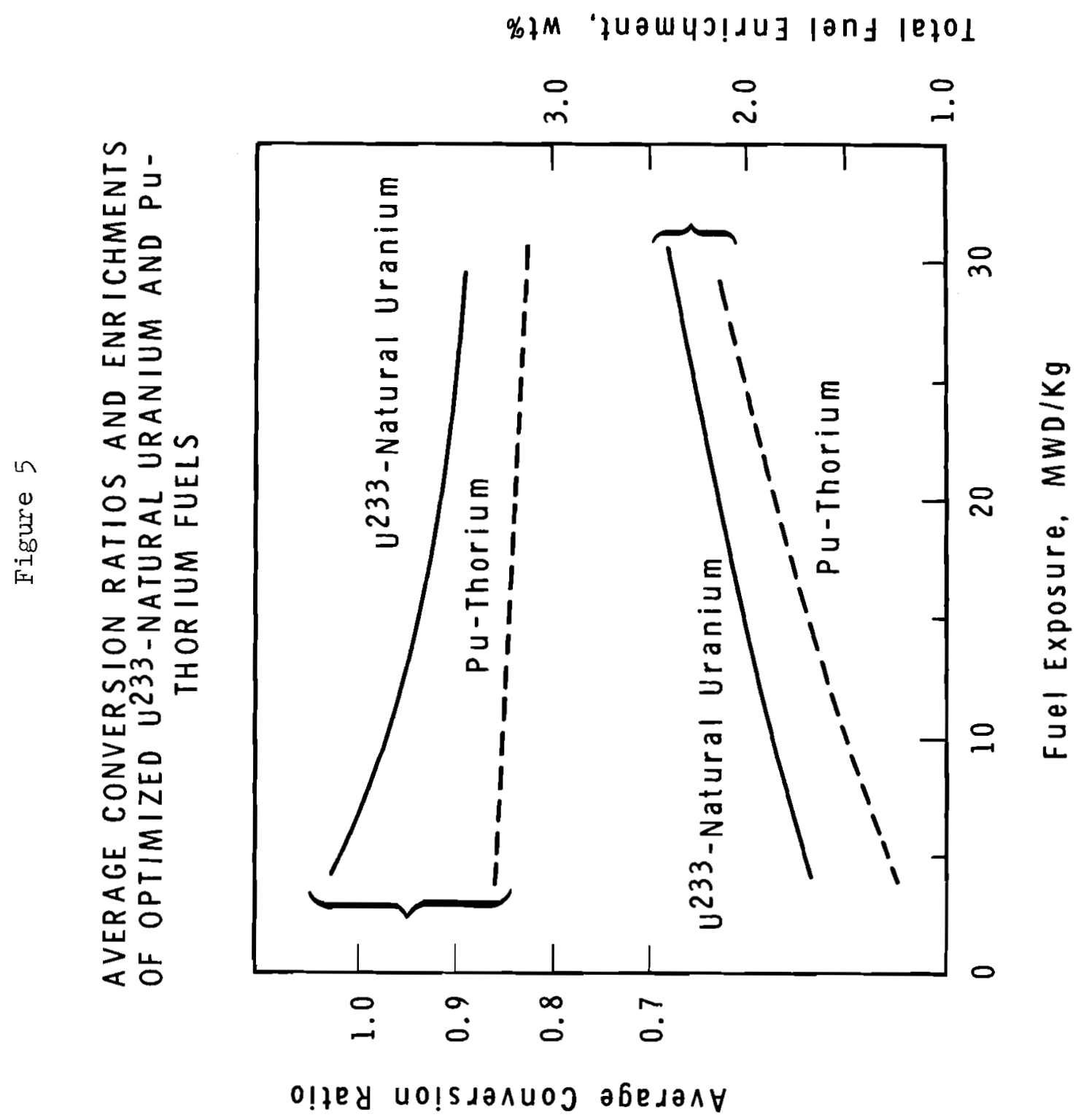


$15 \mathrm{MWd} / \mathrm{kg}$, or 15,000 MWd/MiT. The figure also indicates that the enrichment necessary for U-233-natural uranium to reach an exposure of $15 \mathrm{MWd} / \mathrm{kg}$ is only 2.2\%, which is typical of the enrichment levels proposed for advanced LWR's. These tidy results would be altered if there is an unforeseen resonance absorber among the fission products. Whether there is such an absorber will not be known until burnups are performed in such a spectrum。

The conversion ratio of a realistic plutonium-thoriun fueled HWR is also shown in Figure 5. This conversion ratio does not change much with exposure, owing to the buildup of $\mathrm{U}-233$; and the enrichment of the plutonium-thorium fuel is lower than the U-233-natural uranium fuel because HWR's normally have low neutron losses. It should be noted that plutonium-thorium, when compared to U-235-thorium, has the advantage of not contaminating U-233 with large amounts of U-235 and U-236.

Figure 6 compares the fuel-cycle cost of U-233-natural uranium, slightly enriched uranium, and plutonium-natural uranium as a function of moderator-to-fuel ratios. The point to be made here is that U-233natural uranium optimizes at a moderator-to-fuel ratio of 0.6 , whereas slightly enriched uranium optimizes at 1.7. This means that U-233natural uranium, if used in existing LWR lattices, would not have a lower fuel-cycle cost than slightly enriched uranium fuel. However, U-233natural uranium compared to slightly enriched uranium has a $0.2 \mathrm{mill} / \mathrm{kWh}$ cost advantage when both fuels are in optimized lattices. This cost advantage, however, does not take into account the additional advantage of lower capital costs that might be achieved by doubling the overall reactor power output per unit core volume. This doubling of reactor power is possible because of the larger heat transfer area associated with a tighter lattice.

Now in Figure 7 we will consider an LWR and an HWR that have the same electrical capacity. And we will compare the fuel-cycle cost and conversion ratios for three general fueling methods--namely, direct recycle, cross progeny recycle, and slightly enriched uranium without recycle. Both the LWR and the HWR are shown here for slightly enriched 

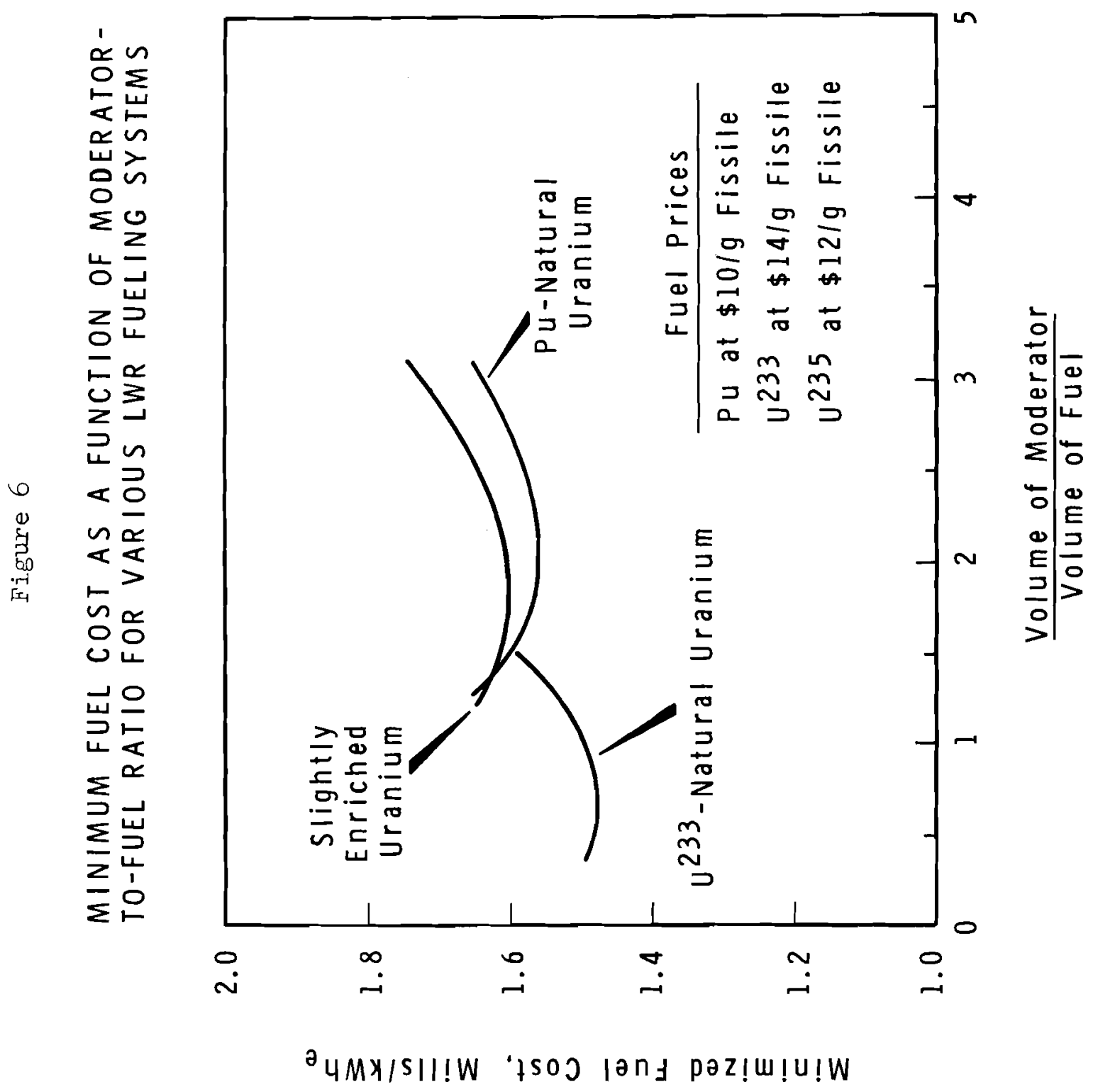
FUEL CYCLE COSTS AND AVERAGE CONVERSION RATIOS FOR OPTIMIZED LWR AND HWR FUELS

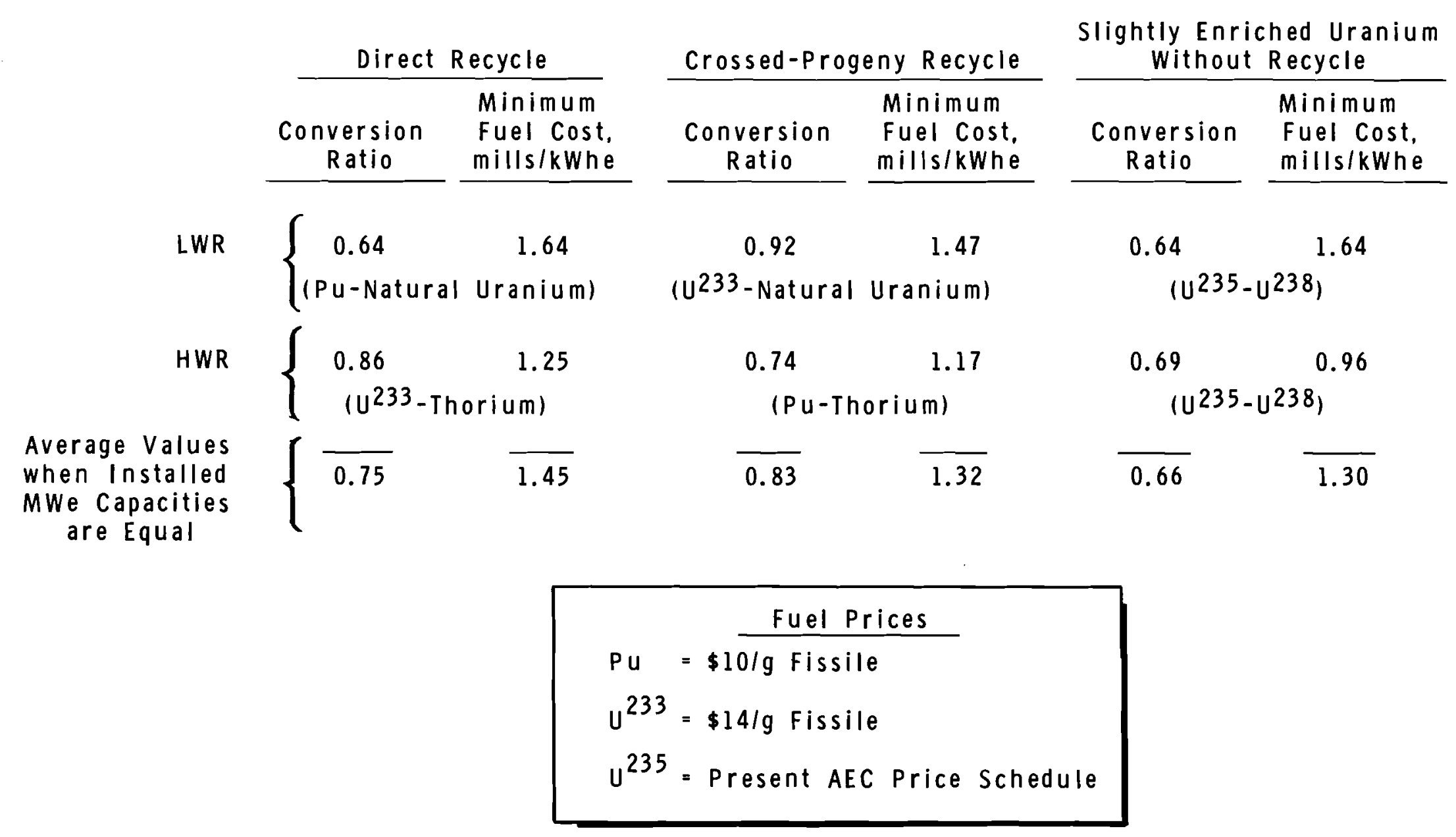


uranium without recycle because this is the fueling system that is presently in-place and its cost should be used as a standard for comparing the other fueling systems. . It should also be made clear that, although the reactor type is the same in each of the three fueling systems, the reactor lattice spacing is different because it has been optimized from a cost standpoint. We begin our comparisons by noting that the HWR using U-233-thorium fuel in direct recycle has a lower fuel-cycle cost and a higher conversion ratio than the plutonium-natural uranium fuel in direct recycle. The HWR fuel-cycle cost, of course, does not include the cost of the $\mathrm{D}_{2} \mathrm{O}$ moderator. Now if the HWR U-233-thorium fuel-cycle cost of $1.25 \mathrm{mill} / \mathrm{kWh}$ is compared with slightly enriched uranium without recycle in an HWR, we see that the 0.96 fuel-cycle cost is substantially less. Also, the average fuel-cycle cost of the HWR and IWR reactors using direct recycle is higher than the average fuel-cycle cost of the HWR and LWR reactors using slightly enriched uranium without recycle--namely, 1.45 to $1.30 \mathrm{mills} / \mathrm{kWh}_{\mathrm{e}}$. However, the average conversion ratio is somewhat higher than that of slightly enriched uranium--namely, 0.75 to 0.66 .

Next, considering the crossed-progeny recycle, we see a considerable cost reduction in the LWR compared to slightly enriched uranium--namely, 1.47 to 1.64 , while the plutonium-thorium HWR is still somewhat higher than slightly enriched uranium--namely, 1.17 to 0.96. However, the average fuel-cycle costs of the crossed-progeny recycle and the slightly enriched uranium without recycle are nearly equal--namely, $1.32 \mathrm{mill} / \mathrm{kWh}$ and $1.30 \mathrm{mill} / \mathrm{kWhe}$. But the conversion ratio is substantially greater; that is, 0.83 to 0.66 . The difference in conversion ratio, however, between crossed-progeny recycle and direct recycle is not as large, being 0.83 to 0.75 . Summarizing then, we can see that the crossed-progeny recycle may be competitive with slightly enriched uranium without recycle, while at the same time showing a substantial improvement in the average conversion ratio.

It should be emphasized that these fuel-cycle cost comparisons are highly dependent on the assumed fuel prices of U-233 and plutonium being $\$ 1 / \mathrm{g}$ fissile and $\$ / \mathrm{g}$ fissile, respectively. We have performed calculations to assess the relative worth of plutonium and U-233 as enriching 
materials for both natural uranium and thcrium. The purpose of the calculations was to determine what price ratio--that is, the price of U-233 to plutonium-would be required to achieve the same fuel-cycle cost. Calculations using plutonium to enrich thorium, and U-233 to enrich thorium, in an HWR show a price ratio of 1.4 , which is consistent with the $\$ 10$ and $\$ 14 / g$ values used thus far for plutonium and U-233, respectively. Further calculations were performed to assess the relative worth of U-233 and plutonium as enrichments for natural uranium in LWR's. These calculations show a price ratio of 1.5 , which reflects the increase in $U-233$ value acquired by the gain in fast effect in tight lattice LWR's. Again, it should be pointed out that this high value of $U-233$ as enrichment for U-238 is dependent on the ease with which U-233 is separated from U-233natural uranium after the fuel is burned.

The crossed-progeny example used thus far was chosen because it showed the greatest economic potential for using thorium in a thermal reactor.* However, plutonium enrichment of thorium may also be of interest in LWR's, because plutonium-thorium exhibits a lower fuel-cycle cost than U-235-thorium. This cost difference is basically due to the large cross section of plutonium, which reduces the enrichment requirement necessary for a given fuel exposure.

Further reductions in the enrichment requirements are possible if the thorium density is reduced. Thorium, having a larger absorption cross section, requires a high enrichment to stay critical; and the inventory charges of this high enrichment make the use of thorium fuels unattractive compared with slightly enriched uranium. Reducing the thorium density could lower fuel-cycle costs as much as 0.15 to 0.3 $\operatorname{mills} / \mathrm{kWh}$.

Figure 8 shows the effect of thorium density on the fuel-cycle costs of a PWR. It should be noted here that the fabrication cost expressed in $\$ / \mathrm{kg}$ for any given density is equal to the fabrication cost at full density--that is, $8.8 \mathrm{~g} / \mathrm{cm}^{3}$--times the ratio of the full density to the actual density. Thus if the full density fabrication cost is $\$ 100 / \mathrm{kg}$, and the density is reduced by $50 \%$, the fabrication cost will double. In other words, the volumetric fabrication cost remains 
Figure 8

THE EFFECT OF THORIUM DENSITY ON THE FUEL CYCLE COST OF A PWR

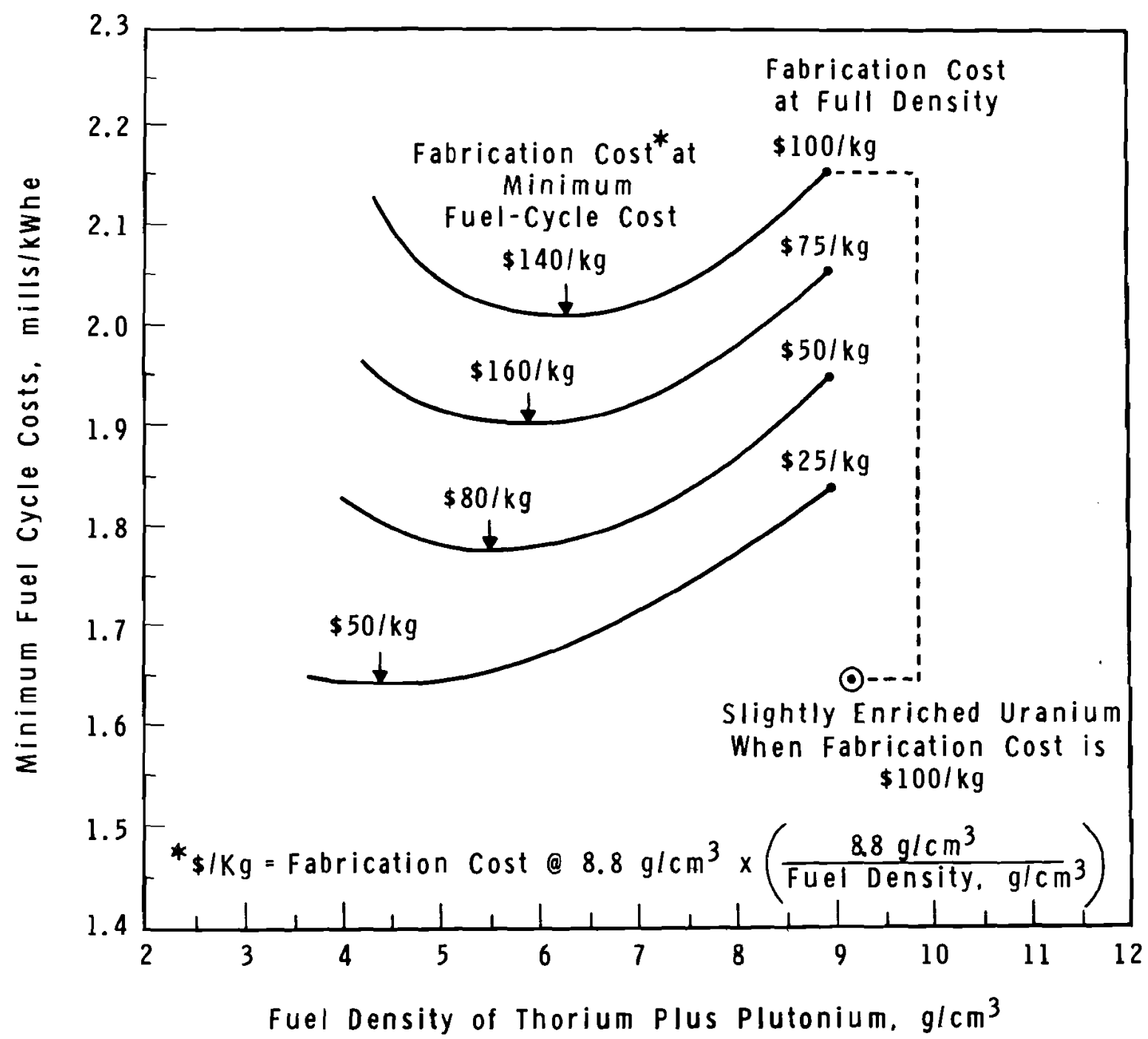


constant. The factors that determine an optimum fuel density are the reduction in inventcry cost and the increase in fabrication cost. Thus if fabrication costs are low compared with inventory costs, a greater reduction in the optimum density will be possible. For example, in the top curve shown in the figure where the full density fabrication cost is $\$ 100 / \mathrm{kg}$, the optimum density is $0.63 \mathrm{~g} / \mathrm{cm}^{3}$, and the fabrication cost is $\$ 140 / \mathrm{kg}$ 。 If we use the bottom curve in the figure as another example, we see that when the full density fabrication cost is $\$ 25 / \mathrm{kg}$ the optimum density is $4.4 \mathrm{~g} / \mathrm{cm}^{3}$, and the fabrication cost is $\$ 50 / \mathrm{kg}$. It should be pointed out that, although these fuel-cycle cost reductions are impressive, the plutonium-thorium fuel still is not competitive with slightly enriched uranium, which is shown as a single point that has the same $\$ 100 / \mathrm{kg}$ full density fabrication cost as the top curve.

An extension of both the crossed-progeny and reduced-density fuel concepts is a fuel form described in Figure 9 as ternary fuels. Ternary fuels consist of U-238 and thorium combined with a plutonium enrichment. The mixture of these materials, which include a high Pu-240 content, has an effective fertile absorption rate equal to that of U-238 or thorium at full density. The reason for this is that the resonance integrals of the three fertile materials $T h-232, \mathrm{U}-238$, and Pu-240, are more nearly equal to their dilute values, and the energies where resonances occur are not overlapping. Furthermore, the reactivity during burnup remains nearly constant, because the depletion of the fuel combination effectively compensates for the burnout of fissile material. Another attractive property of ternary fuels is that the volume made available by reducing the fuel densities may be replaced by a matrix, and the heat conductivity of this combination may be better than that of fulldensity fuel. Thus higher power levels could be maintained without the fuel being melted in the center. A second way of using the extra volume made available by reducing the fuel density would be to construct fuels with extended cooling surfaces. This, too, would increase the heat removal rate per unit reactor volume.

Figure 10 shows a plot of reactivity versus exposure for a ternary fuel whose density is $15 \%$ of a normal $\mathrm{UO}_{2}$ fuel. As you can see, the 
Figure 9

\section{PROPERTIES OF TERNARY FUELS}

- Constant Fuel Fertility When Fuel Density is Reduced

\begin{tabular}{|c|c|c|}
\hline Isotope & $\begin{array}{c}\text { Dilute Resonance } \\
\text { Integral, barns }\end{array}$ & $\begin{array}{l}\text { Location of } \\
\text { Major Resonance }\end{array}$ \\
\hline$T h^{232}$ & 82 & $20 \mathrm{eV}$ \\
\hline$u^{238}$ & 282 & $6 \mathrm{eV}$ \\
\hline $\mathrm{Pu}^{240}$ & 8600 & $1 \mathrm{eV}$ \\
\hline
\end{tabular}

- Constant Reactivity Because Fertile Fuel Burnout Compensates for Fissile Fuel Burnout

- High Heat Flux Because

(1) Conductivity Through Matrices is Better than Conductivity Through Fuel

(2) Cooling Surfaces are Extended 
Figure 10

THE INFINITE MULTIPLICATION FACTOR AS A FUNCTION OF EXPOSURE FOR A REDUCED DENSITY TERNARY FUEL*

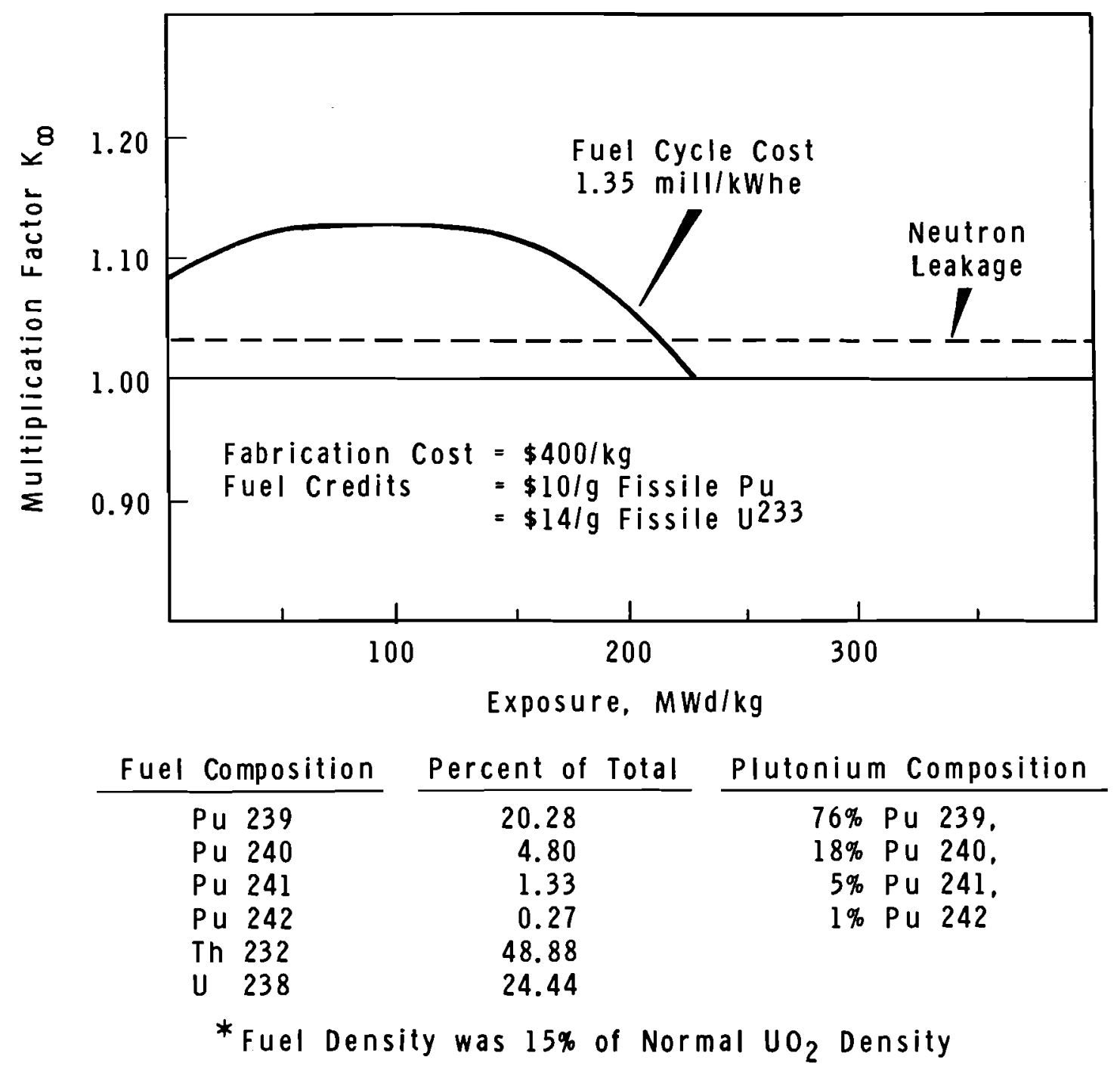


reactivity is quite flat over the exposure. The high fabrication cost and the high fuel exposures are both due to the fuel density being reduced. It should be pointed out that at an exposure of $200,000 \mathrm{MWd} / \mathrm{MT}$ the heat removed from this reduced-density fuel would be about equal to that removed from a full-density fuel whose exposure was $15,000 \mathrm{MWd} / \mathrm{MT}$.

In conclusion, then, we have indicated that (1) the crossed-progeny fuel cycles could be competitive with slightly enriched uranium fuel cycles; (2) crossed-progeny fuel cycles would upgrade present LWR performance, making it a true advanced converter; (3) heavy water reactors fueled with plutonium-thorixim could economically supply the U-233 for the crossedprogeny fuel cycles; (4) unlike U-235-thorium, plutonium-thorium fuel would not contaminate the new U-233 with large amounts of U-235 and U-236; (5) the high enrichment required by thorium fuels could be decreased by reducing the thorium density; and (6) very high specific power and attractive reductions in reactivity swing could be obtained by using thorium, $\mathrm{U}-238$, and plutonium as a ternary fuel. 


\section{DISTRIBUTICN}

\section{Number of Copies}

1

343

4

4

1

186
Division of Reactor Development

AEC, Washington, D. C.

Division of Technical Information Extension

General Electric Company, Richland GETA File Copies

Richland Operations Office

R. K. Sharp

Technical Information Library

P. G. Holsted (2)

University of California, Livermore

Attn: Dr。 James Hadley

Battelle-Northwest

F. W. Albaugh

C. A. Bennett

F. G。 Dawson, Jr.

D. E. Deonigi

R. F. Dickerson

E. A. Eschbach (160)

S. I. Fawcett

H. Harty

P. A. Horton

E. D. Jones, Jr。

B. B. Lane

E. T. Merrill

J. H. Nail

W. I. Neef

R. S. Paul

W. A. Reardon

R. I. Reynolds

W. D. Richmond, Jr .

E. A. Schnaible

J. R. Sheff

R. E. Shippert

R. E. Thompson

C. R. Tipton, Jr.

M. T. Walling, Jr.

Technical Information Files

Technical Publications, 700 Area (2) 


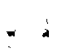

?

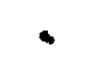
. 